\title{
A imprensa e a memória do futebol brasileiro
}

\author{
Antonio Jorge G. Soares 1,2 \\ Tiago L. Bartholo 2 \\ Marco S. Salvador 3,4
}

https://doi.org/10.5628/rpcd.07.03.368

\author{
1 Universidade Gama Filho \\ Brasil \\ 2 Universidade Federal do Rio de Janeiro \\ Brasil \\ 3 Universidade Estadual do Rio de Janeiro \\ ${ }^{4}$ Colégio D. Pedro II \\ Brasil
}

\begin{abstract}
RESUMO
$\mathrm{O}$ artigo analisa a memória do futebol brasileiro a partir das narrativas produzidas pela imprensa esportiva. Utiliza como material empírico os jornais editados durante as Copas do Mundo de futebol (1998-2002) e os editados durante a Copa do Mundo de 1970. Compara as imagens e narrativas construídas no evento de 1970 com as construídas e mantidas atualmente na memória jornalística, quando rememora a vitória desse campeonato. Conclui-se que os eventos sobre a seleção de 1970 rememorados pela imprensa atual são apresentados a partir da complexa relação entre lembrança e esquecimento que se ajustam às demandas de afirmação da identidade do "futebol-arte" como uma das formas de reafirmação da identidade nacional.
\end{abstract}

Palavras-chave: identidade, futebol e memória

\section{ABSTRACT \\ The press and the memory of the Brazilian soccer}

This article examines the memory of Brazilian soccer through narratives produced by the sporting press. The analyzed material comprises news pieces published during the two consecutive world championships, the World Cup (1998-2002), as well as pieces published during the W orld Cup in 1970. The objective is to compare the images and narratives from 1970 W orld Cup to the narratives of 1998 and 2002 W orld Cups. The analysis indicates that the events referring to the 1970 team narrated by the current press are subject to selection and edition processes that are adjusted to the demands of the identity of the "Brazilian soccer style".

Key-words: identity, soccer, memory 


\section{INTRODUÇÃO}

O artigo investiga a "reconstrução" e a "actual ização" da memória da selecção brasileira de futebol na Copa do Mundo de 1970i. Comparamos as matérias de jornais veiculadas durante a conquista do seleccionado brasileiro na Copa do Mundo de futebol de 1970 com as matérias que rememoram tal conquista nas Copas de 1998 e 2002. O objectivo do estudo é demonstrar como os esquecimentos produzidos sobre a selecção de 1970 são funcionais para reafirmar a identidade do futebol brasileiro, chamado de futebol-arte ou "jogo bonito", bem como, para reforçar as imagens de criatividade e de espontaneidade que os "brasileiros" tanto se orgulham. Nessa direcção, o futebol serve para ilustrar como o terreno da memória é um local de tensões na afirmação das identidades.

A memória no campo da história já rendeu um significativo debate sobre o assunto que gerou uma série de argumentos de distinção conceitual: uma visão positivista a toma como distorção, ideologia, ficção; outra visão a entende como uma das formas de acesso ao passado que reflecte $o$ acontecido no presente e o projeta no futuro(16).

No plano epistemológico, a memória pode ser pensada a partir da relação entre lembranças, esquecimentos e silêncios. Se a lembrança, sempre sel ectiva, é al go quase evidente quando se pensa no conceito de memória, os esquecimentos e os silêncios como categorias de análise não são tão claros e explícitos(12). Eles possuem uma função na construção ou na protecção de identidadesii, logo, merecem uma atenção especial quando entramos nesse campo de estudos.

Os jornais são um dos guardiões da memória social na modernidade. Rememorar qualquer evento que ligue o presente ao passado se tornou um dos motes do jornalismo. No caso do futebol, as narrativas jornalísticas apresentam sua memória resgatando fatos, imagens, ídolos, êxitos e fracassos anteriores, no sentido de construir uma tradição, como um elo entre as gerações dos aficionados pelo esporteii. Os jornais brasileiros que cobriram a Copa de 1970 ao apresentarem jogos e probabilidades de vitória da selecção, contra qualquer adversário, relembravam dramas de derrotas ou vitóriasiv. A construção da imprevisibilidade excita o leitor. Como estratégia jor- nalística, tal acção coloca o presente em continuidade com o passado fornecendo elos identitários entre gerações e apresentando o esporte como um "drama" que faz a identidade ficar em permanente processo de afirmação nesse campo.

A hipótese levantada é a de que as narrativas jornalísticas ao rememorarem, no presente, eventos e personagens da Copa de 1970, esquecem, de forma nãoconsciente, elementos e eventos que não se ajustam à tradição da narrativa do "futebol-arte" que se transforma, em certas ocasiões, em metonímia da nação. O argumento que sustenta a hipótese é: a memória jornal ística esquece e quase apaga as imagens da disciplina, do esforço, do planejamento, da rotina, do treinamento e da ciência, que foram fundamentais na obtenção do sucesso da selecção de 1970. Todavia, tais imagens não se ajustam às imagens identitárias da "arte", da "criatividade", da "malícia" ou "malandragem" do jogador brasileiro imagens hegemónicas em determinadas situações.

\section{METODOLOGIA}

Neste artigo analisamos as reportagens dos jornais 0 Globo e Jornal do Brasil - periódicos de circulação nacional - e das revistas Veja, $M$ anchete, A conteceu, High Sport e M otel Clube M inas Gerais publicadas em 1970. Foram seleccionadas 32 matérias em 1970, 24 matérias dos jornais da Copa de 1998 e 27 da Copa de 2002, todas classificadas a partir das seguintes categorias: a) o "futebol-arte" - técnica corporal singular do brasileiro que identifica o estilo de jogo; b) a valorização da "ciência" no esporte - matérias que enfatizavam o processo científico de preparação física da sel ecção de futebol; e c) a conciliação entre estilo de jogo e ciência. As categorias de análise do conteúdo, segundo Bardin, classificam os elementos de um grupo ou conjunto observando o critério de diferenciação, posteriormente reagrupando-os por intermédio das semelhanças, de acordo com critérios estabelecidos(1).

\section{DESCRIÇÃO E ANÁLISE DOS DADOS}

As narrativas sobre o futebol no Brasil ainda tomam a sel ecção de 1970 como um dos pilares do orgulho na reafirmação de uma identidade positiva. O estilo de jogo da selecção brasileira de 1970 tornou-se a referência do bom futebol que identifica o Brasil. 
Embora datada a construção desse estilo, a constante tensão entre afirmação e perda do estilo estrutura uma narrativa identitária que se pretende atemporalmente como a "natureza" do "ser brasileiro" nesse espaço social. Tal imaginário transforma-se num bem cultural que mobiliza afetos e rende bons debates nos jornais, na televisão e no cotidiano.

Salles e Soares(14) realizaram uma enquête, com 50 entrevistados, homens e mulheres, de diferentes faixas etárias ( 17 aos 60 anos), questionando-os sobre "o que é o melhor do futebol brasileiro?" e "quais são os maiores jogadores da sua história?" As respostas indicam dominantemente os jogadores e as seleções de 1970 e de $1982^{v}$. Os entrevistados fornecem uma profusão de informações sobre lances, gols, resultados e detal hes eivados de emoções. As respostas dos entrevistados indicam que o brasileiro é al guém "festivo", "criativo", "alegre" e "moleque"(14). Essas são as mesmas imagens reforçadas na mídia sobre o futebol brasileiro. Tais dados reforçam as interpretações de vários autores que se debruçaram sobre a relação futebol-sociedade no Brasil(5, 8, 10, 15, 18, 21, entre outros). Deve-se ressaltar que a memória, quando accionada, funciona como um mecanismo fundamental de reforço identitáriovi.

O papel da preparação física no treinamento da selecção de 1970 foi amplamente divulgado nos periódicos jornalísticos durante a Copa de 1970, tais veículos cobriram desde a pré até a pós-temporada do evento.

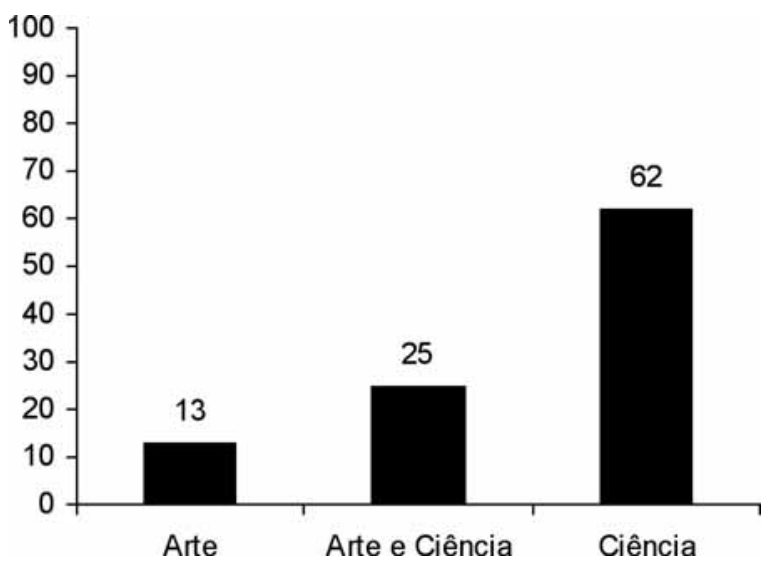

Figura 1. dados colectados nos periódicos durante a Copa de 1970
Do total de 32 matérias que seleccionamos durante o ano de 1970, 20 reportagens ou aproximadamente $62 \%$ do total se referem ao trabalho da preparação física construída a partir de bases científicas (Figura 1). Não podemos esquecer que os governos ditatoriais pós-1964 tinham investido na imagem de um país que estaria se modernizando. Nessa direcção, ciência, tecnologia e planejamento eram temas que estavam na agenda política e se difundia por outros sectores (17). Constatamos apenas quatro narrativas jornalísticas (aproximadamente 13\%) que tratam especificamente do tema "futebol-arte" ou estilo de jogo. A ênfase na preparação física, na modernização do futebol brasileiro, estava de certa forma vinculada ao avanço dos conhecimentos no campo dos estudos sobre treinamento e exercício físicos e à derrota na Copa de 1966, chamada no Brasil de "Copa da força", na qual a eficácia do estilo brasileiro foi colocado em questãovii.

A memória sobre o triunfo na Copa de 1970 presente nos jornais durante a Copa do Mundo de 1998, indica um processo de esquecimento das imagens do planejamento, da disciplina e do treinamento, este construído a partir de bases científicas, em favor do louvor e da exaltação do "futebol-arte".

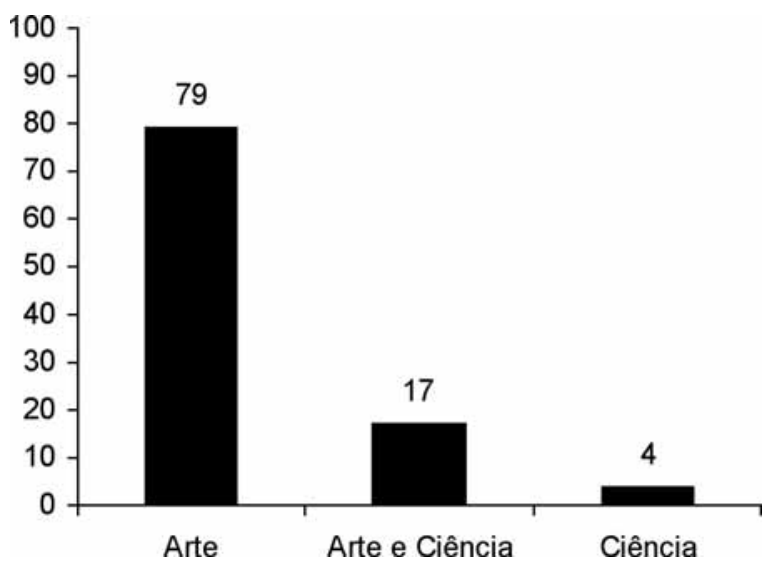

Figura 2. Dados colectados nos periódicos durante a Copa de 1998 
Se, em 1970, o "estilo de jogo" foi pouco enfatizado pelos jornais, em detrimento da novidade da valorização da aplicação de conhecimentos científicos no futebol, em 1998 observamos exactamente o quadro inverso. Do total de 24 matérias que colectamos 19 narrativas (aproximadamente 79\%) descrevem o estilo de jogo como "magia", "genialidade" e "arte" do futebol do passado (Figura 2). Os jogadores e membros da comissão técnica que integraram a selecção de 1970, quando entrevistados na actualidade, tecem comentários e análises que indicam que o futebol brasileiro está perdendo o estilo de jogo que o identificava no passado. A memória da selecção de 1970 acaba por idealizar um estilo de jogo que funciona como exemplar para avaliar o futebol no presente. $\mathrm{O}$ ato de rememorar indica a necessidade de resgate desse estilo. A retórica da perda do futebolarte promove um duplo movimento: de um lado busca resgatar a forma singular de uso do corpo no jogo, de outro, auxilia a delimitar o que seria esse estilo e, por extensão, o que definiria sua identidade. No levantamento realizado durante a Copa de 1998, as narrativas que conciliam o estilo de jogo com o planejamento científico somam 4, aproximadamente $17 \%$, e somente uma matéria colectada trata exclusivamente do treinamento, da ciência e do planejamento como bases fundamentais em 1970 - aproximadamente $4 \%$. Isso configura que os esquecimentos sociais do trabalho ancorado em bases científicas na preparação da selecção de 1970 é secundarizado em favor do discurso identitário do "jogo bonito". A Copa de 2002 segue a mesma tendência das narrativas encontradas nos periódicos em 1998 quando relembra a Copa de 1970. Num total de 27 matérias sobre as memórias da Copa de 1970, identificamos 24 narrativas cujo conteúdo aborda o estilo de jogo bonito, aproximadamente $89 \%$, exaltando o futebol do passado como o "verdadeiro futebol brasileiro". As matérias que descrevem o treinamento em conciliação com o estilo totalizam apenas 3 reportagens ( $11 \%$ aproximadamente). Por fim, não obtivemos registos $(0 \%)$ de matérias que rememorassem especificamente o papel específico do planejamento na conquista de 1970 (Figura 3). O esquecimento, nos dias de hoje, sobre a importância do Planejamento Méxicoviii naquela vitória é tácito.

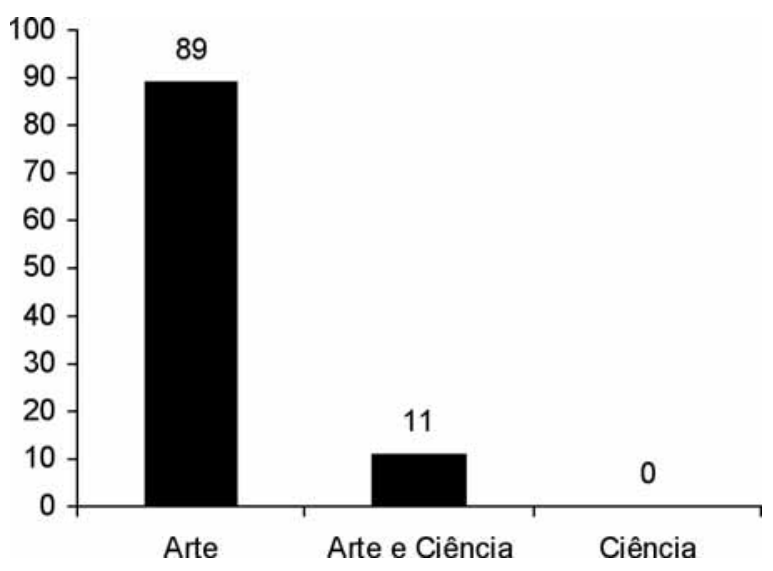

Figura 3. Dados colectados nos periódicos durante a Copa de 2002

Um dado relevante é que os principais jogadores da selecção de 1970 ocupam actualmente significativos espaços na mídia, sejam como comentaristas, treinadores, colunistas ou como pessoas públicas - Pelé, Zagalo, Parreira, Tostão, Rivelino, Gérson, Carlos Alberto Torres, para citar al guns dos principais actores. Esses actores possuem "voz" e são a memória viva nas páginas dos jornais, "fazendo" notícia, sendo "objecto" da notícia e lutando para não caírem no esquecimento.

As análises das matérias sobre a Copa de 1970, durante as Copas de 1998 e 2002, tomam o êxito daquele sel eccionado como referência para comparar a qualidade do futebol na actualidade. A memória traz, como imagem dominante, a sel ecção tricampeã do mundo habitada por "génios da bola" que dignificaram o "verdadeiro futebol brasileiro".

[Titulares Absolutos na Seleção dos Nossos Sonhos] [...] Tostão e Pelé. A lguém duvida de que este time, mesmo sem os dois zagueiros centrais, ganharia fácil uma Copa do M undo de campeões mundiais de todos os tempos? Claro que não. $0 \mathrm{~s}$ craques dessa sel eção atemporal estão na França vendo de perto uma seleção brasileira da qual qualquer um deles seria o titular absoluto ( $0 \mathrm{Globo}$, 28/06/1998, p. 8).

O debate em torno da qualidade do futebol a partir dos diferentes contextos históricos é extenso. A dis- 
cussão se Pelé, Garrincha, Rivelino e Tostão teriam o mesmo desempenho no actual contexto, no qual a vel ocidade e a marcação rigorosa são imperativas, aparece, por exemplo, em vários programas e colunas esportivasix. A selecção de 1970 representa a afirmação do "futebol-arte". Notemos, no entanto, que se verificam nos jornais do presente tensões em torno da imagem idealizada no estilo de jogo. Essas tensões podem estar revelando os novos jogos identitários entre o global, o nacional e o local $(2,15)$. Vejamos a seguinte afirmação do jornalista Aydano André Mota:

Q ualquer que seja 0 destino brasileiro na Copa de 2002 deve-se consignar: será, pelos séculos afora, um prazer assistir ao futebol a vapor, aquelas imagens espetaculares, quase ficção. 0 eterno show de bola. M as já passou da hora de encerrar comparações [...]. A separar os dois, há um abismo de evolução tecnológica, científica que transfigurou o esporte. É como comparar tijolo com vaca. [...] Ronaldinho, Rivaldo, R onaldinho Gaúcho e al guns ( pou$\cos )$ outros não merecem ser condenados pela época em que vivem $\mathrm{X}$. São craques incontestáve's, como demonstram suas biografias. São o verdadeiro futebol brasileiro - 0 que ganha. A o contrário de $D$ enílson ${ }^{x i}$, essa inutilidade rebolativa que emplacou a segunda Copa consecutiva como redenção moderna do futebol a vapor (Jornal do Brasil, 23/06/2002, p. 3).

Helal e Soares(9), analisando essa tensão interna no jornalismo esportivo, completam: “Esse tipo de voz vem surgindo pouco a pouco na imprensa como uma reação de crítica interna ao jornalismo esportivo e, talvez, um embate entre geraç̧ões de jogadores, torcedores e jornalistas". Observemos que mesmo essa crítica esquece que o futebol da selecção de 1970 estava afinado com o que existia de mais moderno em termos de preparação física e treinamento. Notemos também que um artigo de Joaquim Ferreira dos Santos (Jornal do Brasil, 7/ 10/2001, p. 33) deu origem a um debate sobre o tema ao avaliar que o futebol de 1970 pelo videoteipe era "chato, medíocre e que naquela época era muito fácil de se jogar". Imediatamente, esse artigo gerou resposta na coluna do Tostão e no artigo de Augusto Nunes na edição do J ornal do Brasil, de 14/ 10/2001, na p. 26.
O sentimento de afirmação da identidade pelo futebol brasileiro vinha sendo desenhado desde a década de 1930, mas sua consolidação ocorreu com a conquista do bicampeonato num curto espaço de quatro anos (1958-1962). Entretanto, como no esporte o diálogo entre passado e presente é permanentemente tenso, a derrota na Copa de 1966 foi lida como decadência e atraso do futebol, na qual a "força" predominou sobre a "arte" em relação às novas tecnologias do treinamento físico e táctico. A imagem de atraso é constante na tradição das análises sobre o Brasil que pode ser datada pelo menos desde o sécuIo XIX até nossos dias(13). Em matéria jornalística João Saldanha - famoso jornalista e que foi técnico da seleção de 1970 durante as eliminatórias - explicita essa idéia:

A imoré $M$ oreira deu 0 grito de independência de nosso futebol tão agarrado às velhas fórmulas. [...] não é mais possível continuarmos vivendo do passado. A quilo que era bom em 1958 e 1962 já não serve mais. Vou mudar tudo, de outra forma sucumbiremos. [...] Uns 0 apoiaram incondicionalmente ( $\mathrm{A}$ imoré) porque tinha razão. [...] M as houve uma parte, cerca de metade, que não 0 apoiou. É sempre assim, quando as coisas novas são apresentadas. Ainda mais que sempre, com a boca cheia, os conservadores falavam das vitórias de 58 e 62, esqueciam-se com muita facilidade do fracasso de 1966, na Inglaterra (0 Globo, 25/6/1970, p. 22).

A vitória na Copa de 1970 viria recuperar triunfalmente o posto de "melhor futebol do mundo" e o retorno do orgulho nacional, à custa daquilo que os analistas e protagonistas da época entendiam como reformulação e modernização do futebol nacional. U ma dessas mudanças foi a introdução do pioneiro e minucioso projecto de preparação física, montado por especialistas da época na Escola de Educação Física do Exercito (EsEFEx), com bases científicas adquiridas por intermédio de intercâmbio com países estrangeiros e com a própria produção interna(20). Algumas matérias jornalísticas explicitam a influência da preparação científica naquele seleccionado. U ma delas é uma entrevista com João Sal danha realizada pela revista $\mathrm{H}$ igh Sport, poucos meses antes da Copa, em Março de 1970: 
Nós, do Brasil, sabemos de tudo que se passa a respeito de métodos de preparação física no mundo. 0 intercâmbio é muito grande, as escolas de Educação Física, que existem em todos os lugares, se correspondem, trocam informações. 0 s clubes brasil eiros estão excursionando constantemente [...]. Faremos testes de Cooper (resistência, flexibilidade, velocidade e capacidade pulmonar), e de acordo com os resultados obtidos, dividiremos os jogadores em três ou quatro grupos distintos, conforme suas características [...] N aturalmente que faremos alguns treinamentos especiais, por exemplo com os goleiros (H igh Sport, 03/1970, pp. 28-30).

A valorização do treinamento e dos métodos científicos ficava explícita nos jornais e nas revistas da época, tendo nos membros da comissão seus principais porta-vozes:

Para A dmildo Chirol, o principal motivo do excelente estado físico dos jogadores brasileiros foi a estada de 21 dias em Guanajuato porque aumentou em quase o dobro a taxa de glóbulos vermel hos do sangue, num período ideal para adaptação à altitude (Jornal do Brasil, 10/6/70, p. 22).

Observamos, de acordo com as narrativas jornalísticas, que a introdução de métodos científicos na preparação do sel eccionado brasileiro de futebol para a Copa de 1970 era comum nas páginas esportivas da imprensa no período anterior à referida Copa, tomando um vulto cada vez mais significativo no transcorrer do evento, a cada vitória da equipe. Isso confirma a importância dos referidos métodos como suporte imprescindível na conquista do tricampeonato.

[...] segundo A dmildo Chirol, já temos um título: somos campeões mundiais do preparo físico, o que foi comprovado por um órgão da Organização M undial de Saúde [...] para chegar a esta perfeição atlética o Brasil seguiu o programa executado com todo o rigor científico. Para começar escoIheu uma equipe excepcional de preparadores físicos, integrada por Admildo Chirol, o capitão Coutinho (o melhor conhecedor do assunto no exército brasileiro, inclusive com o estágio no organismo que cuida da preparação dos cosmonautas norte-americanos) e Carlos A Iberto Parreira que conhece a fundo os métodos europeus (Jornal do Brasil, 11/ 7/ 1970, Caderno B, capa).
A última matéria citada não economizou elogios à racionalidade científica, pois afirma categoricamente que, seja qual for o resultado da Copa, já detínhamos (ou nos auto-outorgávamos) o título de campeões do "preparo físico".

A introdução da ciência no esporte não se limitava apenas ao treinamento físico. A psicologia esportiva tinha sua contribuição a dar no planejamento da pre paração da sel ecção. O argumento que sustentava tal intervenção se baseava no fato que os jogadores seriam inseridos em um novo ambiente, longe da família e poderiam sofrer diferentes tipos de pressão psicológica: “[...] a correta preparação psicológica foi durante essa competição, e fatalmente o será na próxima Copa do M undo, fator mais que importante para condicionar as excelentes performances aos dotes de cada um" (M otel Clube do Brasil, 1970, p. 14).

A narrativa do suporte científico na preparação das equipes era patente naquele contexto. O relatório da Federação Internacional de Futebol (FIFA) (7) aponta que muitas selecções na época estudaram cientifica mente o melhor processo de adaptação fisiológica dos atletas à altitude. A altitude era encarada como um forte adversário das selecções acostumadas a jogar no nível do mar. No caso brasileiro, o professor Lamartine Pereira DaCosta (1967) já havia publicado internacionalmente em 1967 o trabal ho sobre "altitude training", sobre as estratégias de adaptação à altitude. Esse método foi utilizado em todo processo de adaptação física dos jogadores durante a competição(20). O debate sobre o suporte científico dando base aos programas de treinamento e adaptação biológica estava na pauta de nossos jornais em 1970. Como uma corrida à conquista do espaço, em voga na época, todos os países estavam preocupados com a melhor estratégia de adaptação de seus atletas e a mídia tornava notícia esse tema:

[...] o Brasil optou inicialmente por Guadalajara, de onde seguiu, uma semana depois, para a cidade de Guanajuato, distante três horas e meia de automóvel, a uma altitude bem superior. 0 s ingleses fizeram o contrário. Para princípio de atividade, decidiram passar doze dias na capital mexicana, relaxando o corpo e espírito. Terminado esse estágio, viajarão para Bogotá e Quito com a finalidade de jogar a uma altitude de 2.400 metros acima do nível do mar [...] Quem está certo: o Brasil, que foi diretamente 
para Guadalajara, ou a Inglaterra, que prefere excursionar, voltando em cima da hora para disputar o campeonato mundial? (M otel Clube M inas Gerais, 1970, p. 14).

As evidências apresentadas indicam como os jornais ressaltavam os processos de treinamento baseado nos conhecimentos científicos da época. Todavia, as imagens que traduziam a "arte" do jogador brasileiro não eram negligenciadas nas narrativas. Naquele momento as narrativas cientifizantes do futebol se conciliavam com as narrativas identitárias de nosso futebol:

[...] Zagalo abriu os olhos do futebol internacional para a nova concepção do time que não se divide mais em ataque e defesa [...] o título de 70 deve ser exaltado com uma associação de valores artísticos e criativos. "A técnica de Pelé e Gerson só levou o futebol brasileiro a final do A steca porque um comando competente soube executar um programa de preparação física e de habilitação tática, a meu ver tão preciosos quanto o espírito de sacrifício dos jogadores" [...] submetido[s] a treinamento rigoroso e criterioso, o jogador brasileiro adquire um nível atlético que permite realizar plenamente sua luminosa técnica e como é incomparável em habilidade, leva a loucura e exaure o rival dos pés a cabeça, tentando em vão bloquear a circulação da bola (Jornal do Brasil, 23/6/1970, p. 35).

Ao aliar a sincronização de um balet europeu à improvisação quase mágica de seus atacantes a sel eção brasileira impôs um padrão de jogo que tonteou os europeus e deixouos até agora sem justificativas lógicas para goleada (Jornal do Brasil, 5/06/70, p. 25).

A sincronização do balé europeu indica treino, persistência e perfeição conseguidas ao custo da disciplina e do esforço. Noutra direcção, a narrativa traz a ideia de improvisação que se ajusta à imagem mais próxima da natureza e da sabedoria extraída de um contexto de necessidade, além da ênfase nas características étnicas, indicando a vel ha combinação, ao estilo freyreano, da irracionalidade com a racionalidade, da miscigenação cultural formando um equilíbrio de antagonismos(19).

Essa matéria, publicada após o primeiro jogo do Brasil, denota uma tendência jornalística iniciada pós-1966 que encontra nos resultados de sucesso do seleccionado uma espécie de confirmação de que não bastaria somente o "talento" ou a "arte". O futebol brasileiro precisava se modernizar sem perder sua identidade.

Como já argumentamos anteriormente, a ideia da ciência, do treinamento e do sacrifício conciliadas com as imagens identitárias do futebol brasileiro presentes durante e imediatamente após a conquista de 1970 vão-se perdendo e sendo esquecidas na memória jornalística. Os jornais durante as Copas de 1998 a 2002 ligam o presente ao passado ressaltando imagens sobre as selecções do passado com marcas da criatividade, autenticidade e singularidade do jogador brasileiro. Nas matérias seleccionadas n'0 Globo de 1998 e 2002, encontramos raras menções ao processo de treinamento físico e tático da selecção de 1970. As imagens que dominam são as da "arte" e da criatividade de nosso jogador:

1970: foram as páginas mais gloriosas da história da sele ção brasileira e provavelmente de qual quer sel eção campeã mundial. A equipe do Brasil de 1970, pelo talento de seus craques, pela tática e pela beleza de seu futebol, é a melhor de todos os tempos (0 Globo, 30/6/ 2002, p. 4).

$\mathrm{Na}$ Copa de 70, um verdadeiro dream-team do futebol venceu os sete jogos disputados e exorcizou parte dos fantasmas de 1950 ao derrotar o U ruguai nas semifinais por 3 a 1 (0 Globo, 8/7/1998, p. 12).

[Referindo-se a Zagalo] Em 70, dirigiu a seleção mais brilhante da história do futebol brasileiro (0 Globo, 20/6/1998, p. 1).

[Denílson identificando-se como continuador da tradição] - A cho que os meus dribles são a alma do futebol brasileiro. Esse jeito de jogar nos consagrou ( 0 Globo, 4/6/2002, p. 4).

Zagal lo sentencia: “Tenho saudades daquele futebol de arte, alegre e ofensivo. Não havia tanta velocidade, mas a preocupação com a marcação também era bem menor. Era realmente mais bonito - disse, incluindo-se nos times das viúvas de 70" (0 Globo, 22/6/1998, p. 3). Os conteúdos das matérias definem os recortes históricos elegendo os seus mitos em relação ao glorioso passado, nomeando os seus heróis e façanhas e rel egando ao esquecimento marcas que possam entrar em contradição com a identidade do futebol brasileiro. O planejamento geral, que incluía o treino técnico, táctico e físico, é secundarizado na actualidade na medida em que contraria a ideia do "improviso" e do "dom" dos jogadores brasileiros. 


\section{CONCLUSÃO}

Os esquecimentos são essenciais na ressignificação do passado para garantir a continuidade e actualização da tradição. As narrativas jornalísticas de 1998 e 2002, quando trazem à tona a memória sobre a Copa de 1970, esquecem o discurso da ciência, do treinamento físico e do planejamento que estiveram fortemente marcados nos jornais que cobriram os eventos em 1970.

Os jornais, ao apagarem o processo de racionalização do treinamento de 1970, vendem a imagem que os brasileiros alimentam sobre "eles próprios". Todavia, algumas narrativas, ainda que modestas, já aparecem em reação a esse processo de glorificação ao passado, tornando tensa a relação entre passado e presente, entre o local e o global.

Por fim, se por um lado, o esquecimento do treinamento e do planejamento com base em conhecimentos científicos reforça a identidade do futebol brasileiro, por outro, apaga da memória o importante papel que a educação física, a medicina desportiva e seus respectivos profissionaisxii tiveram nesse glorioso momento da história do futebol brasileiro. Em outras palavras, o papel da educação física e da medicina desportiva é esquecido em favor das narrativas identitárias do "dom" do jogador brasileiro.

\section{AGRADECIMENTO}

Financiamento: CNPq e CAPES.
NOTAS

i A conquista da Copa do Mundo de futebol de 1970 foi o terceiro título mundial conquistado pelo Brasil nessa modalidade (1958, 1962, 1970). O time terminou a competição invicto, vencendo na final a seleção italiana pelo placar de $4 \times 1$. O Brasil tornava-se, naquele momento, a primeira nação a sagrar-se três vezes campeã, obtendo o direito de ter a posse definitiva da taça Jules Rimet.

ii Identidade aqui é conceituada como "uma norma de vinculação, necessariamente consciente, baseada em oposições simbólicas"(4).

iii Sobre a importância da dimensão histórica do evento esportivo, Boyles e Raynes escreveram: "One of the particular appeals of sport, for both media and supporters, is the extent to which the narratives or stories which surround sport act as a bridge between the present and the past. Sporting events need to have a longevity to feel important"(3).

iv Durante a Copa de 1970 pudemos acompanhar que a imprensa rememorava as derrotas do passado - Copa de 1950 e 1966 -, assim como os êxitos de 1958 e 1962 na construção de vínculos com a memória.

vA seleção de futebol que disputou a Copa do Mundo de 1982 é vista, por grande parte da imprensa, apesar de ter sido derrotada nas semifinais pela Itália, como uma seleção que resgatou o futebol-arte e, por isso, merecedora de grande respeito da mídia e da população.

vi Lovisolo(11) afirma sobre o papel da memória: “A memória histórica se apresenta idealmente como âncora e plataforma. Enquanto âncora possibilita que, diante do turbilhão da mudança e da modernidade, não nos desmanchemos no ar. Enquanto plataforma permite que nos lancemos para o futuro com os pés solidamente plantados no passado criado, recriado ou inventado como tradição".

vii Em 1966 a preparação física e os conhecimentos científicos dos europeus teriam, segundo os analistas, superado o estilo de jogo dos brasileiros. A imprensa, entre muitas outras reclamações e racionalizações, vociferava que o futebol brasileiro deveria modernizar-se e acompanhar as inovações. O estilo de jogo, a "arte", teria caído por terra diante da "força" e da disciplina física e táctica dos europeus.

viii Planejamento México foi o nome dado para o plano de preparação realizado pela selecção brasileira de futebol para disputar uma competição em grandes altitudes(20).

ix Fica evidente que estamos diante de um tipo de narrativa própria do universo esportivo. No campo da ciência, principalmente na hard science, esse tipo de comparação não faz sentido. O passado é visto como parte da tradição de um determinado campo científico.

× Ronaldinho, Ronaldinho Gaúcho e Rivaldo foram titulares da equipe brasileira campeã da Copa do Mundo de 2002.

xi Denílson, atacante conhecido por seus dribles que relembram o "antigo" futebol brasileiro, participou das Copas do Mundo de 1998 e 2002.

xii Graças às pesquisas e à aplicação de um trabalho científico desenvolvido em equipe, os profissionais de educação física que compunham a comissão técnica da Copa de 1970: Cláudio Coutinho, Admildo Chirol e Carlos Alberto Parreira, em parceria com o trabalho pioneiro sobre "altitude training" do professor Lamartine Pereira DaCosta, influíram directamente no êxito da conquista do tricampeonato em 1970.

\section{Antonio Jorge G. Soares}

Rua Theodor Herzl, 56/ apartamento 103

Botafogo

CEP 22260030. Rio de Janeiro/ RJ

Brasil

E-mail: antoniojsoares@pq.cnpq.br 


\section{REFERÊNCIAS}

1. Bardin L (1997). A nálise de conteúdo. Lisboa: Edições 70.

2. Bartholo TL, Soares AJ, DiBlasi F, Salvador, MAS (2004). A pátria de chuteiras está desaparecendo? In: A nais IX Congresso Brasileiro de $\mathrm{H}$ istória do Esporte, Lazer e Educação.Recife: Universidade Federal de Pernambuco. p 340-349.

3. Boyle R, Raynes R (2000). Power Play: sport, the media and popular culture. Edinburgh: Pearson Education Limited.

4. Cuche $D$ (1999). A noção de cultura nas ciências sociais. Bauru: EDUSC.

5. DaCosta LP (1967). Altitude training. Sport International (36): 19-23.

6. DaMatta R (1982). U niverso do futebol: esporte e sociedade brasileira. Rio de Janeiro: Pinakotheke.

7. FIFA (1972). World Cup México 70. Official FIFA Report. Swiss: FIFA.

8. Guedes S (1998). 0 Brasil no campo de futebol: estudos antropológicos sobre os significados do futebol brasileiro. Niterói: EDUFF.

9. Helal R, Soares AJ (2002). O declínio da pátria de chuteiras: futebol e identidade nacional na Copa do Mundo de 2002. In: Anais XII COM PÓS-A ssociação dos Programas de Pós-graduação em Comunicação. Recife: UFPE. $p$ 401-412.

10. Leite Lopes JS (1994). A vitória do futebol que incorporou a pelada: a invenção do jornalismo esportivo e a entrada dos negros no futebol brasileiro. R ev da USP - D ossiê Futebol (22): 64-83.

11. Lovisolo H (1989). A memória e a formação dos homens. Estudos H istóricos-FGV 2 (3): 16-28.

12. Pollak M (1989). Memória, esquecimento, silêncio. Estudos Históricos-FGV 2 (3): 3-15.

13. Reis JC (1999). As identidades no Brasil: de Varnhagen a FHC. Rio de Janeiro: Editora FGV.

14. Salles JG, Soares AJ (2004). Soccer, the game of passion memories of Brazilian fans. The FIEP bulletin (74): 418-422.

15. Salvador MS (2005). A memória da Copa de 1970: esquecimentos e lembranças do futebol na construção da identidade nacional (Tese). Rio de Janeiro: Programa de Pós-Graduação em Educação Física. Universidade Gama Filho.

16. Silva HR (2002). Rememoração/ comemoração: as utilizações sociais da memória. Rev Bras Hist 22 (44): 425-38.

17. Skidmore T (1988). Brasil: de Castelo a Tancredo (19641985). Rio de Janeiro: Paz e terra.

18. Soares AJ (1994). M alandragem, futebol e identidade. Vitória: Secretaria de Produção e Difusão Cultural/UFES.

19. Soares AJ (2003). Futebol brasileiro e sociedade: a interpretação culturalista de Gilberto Freyre. In: Alabarces, P. (ed.). Futbologías: fútbol, identidad y violencia en A mérica Latina. Clacso-Grupo de Trabajo Deporte e Cultura. Buenos Aires: Consejo Latinoamericano de Ciencias Sociales, 145-162.

20. Soares AJ, Salvador MS, Bartholo TL (2004). O futebol arte e o Planejamento México na Copa de 70: as memórias de Lamartine Pereira DaCosta. R ev M ovimento 10 (3):113130.

21. Vogel A (1982). O momento feliz, reflexões sobre o fute bol e o ethos nacional In: DaMatta R. (ed.). U niverso do futebol: esporte e sociedade brasileira. Rio de Janeiro: Pinakotheke, 75-114.

\section{OUTRAS FONTES}

Arquivo pessoal do professor Lamartine Pereira DaCosta. Jornal do Brasil, 31 maio 1970 - 30 jun 1970. Jornal do Brasil, 23 jun 2002. Jornal O Globo, 25 maio 1998 - 8 jul 1998. Jornal O Globo, 28 maio 2002 - 30 jun 2002. Revista High Sport, (51), mar 1970.

Revista M otel Club 